\title{
A Repetição Intergeracional e o Significado Atual da Deficiência Auditiva
}

\author{
Isa Gonçalves Rezende ${ }^{1}$ \\ Marilene Krom \\ Midori Otake Yamada \\ Universidade de São Paulo
}

\begin{abstract}
RESUMO - Por meio de um enfoque integrado da visão sistêmica, terapia familiar, abordagem intergeracional e leitura instrumental mítica, o presente estudo buscou compreender a família de um sujeito com deficiência auditiva, reconhecer mitos familiares, bem como estabelecer relações entre estes mitos e o significado atual por ele atribuído a sua deficiência. Para coleta de dados foram utilizadas entrevistas semi-estruturadas, as quais foram analisadas qualitativamente. Foram identificados os mitos da união, da deficiência auditiva e da luta pela sobrevivência. A repetição da deficiência auditiva em vários membros da família gerou rigidez das pautas de ajuda e cuidado determinadas pelo mito da união e das fronteiras com o mundo externo. Ao identificar os conteúdos que atravessam intergeracionalmente a família, pôde-se garantir a possibilidade de encontrar novos caminhos para lidar com a deficiência, ampliar a visão do contexto e confirmar a necessidade da participação familiar na reabilitação global do sujeito.
\end{abstract}

Palavras-chave: terapia familiar; processos intergeracionais; mitos familiares; deficiência auditiva.

\section{The Intergenerational Repetition and the Actual Meaning of Hearing Disorders}

\begin{abstract}
The present clinical case study used a systemic perspective, concepts of family therapy, an intergenerational approach and mythic instrumental reading to understand the family of a subject with hearing impairment. The objective was to recognize the family myths and to establish the relationships between these myths and the present day meaning assigned by him to his deficiency. A semi-structured interview was used to gather information. A qualitative analysis of the data allowed the identification of myths regarding the hearing impairment, family unity, and the struggle to survive. The presence of hearing impairment in other members of the family has generated rigidity in the rules regarding help and care. Such rigidity is related to the myth of family unity and to the frontiers that have been established with the external world. The identification of the intergenerational contents that cross over the family history generated the possibility to find new ways to deal with the impairment. It also provided an overview of the family context and confirmed the necessity of family participation in the rehabilitation process.
\end{abstract}

Key words: family therapy ;intergenerational processes; family myths; hearing impairment.

Atualmente, com a flexibilização do paradigma cartesiano, surge uma nova perspectiva que considera a inter-relação e interdependência existentes entre os fenômenos biológicos, físicos, psicológicos, sociais e culturais.

A teoria sistêmica surge como uma nova visão da realidade. Bertalanffy (1967) afirma que todo e qualquer organismo é um sistema, que implica a existência de uma ordem dinâmica entre vários componentes e processos em mútua interação.

Partindo dessa concepção, a família pode ser vista funcionando como um sistema. Por volta dos anos 1950, iniciou-se o desenvolvimento dos pressupostos básicos da terapia familiar. De acordo com Umbarger (1983), a terapia familiar estrutural converte as abstrações da teoria geral de sistemas em descrições da vida cotidiana da família e em prescrições para a intervenção terapêutica.

Com base nessa abordagem, a estrutura familiar apresenta princípios identificados com as propriedades presentes nos

1 Endereço: Rua João de Laet, 719. CEP 02410 010. São Paulo-SP. Email: lurocca@bol.com.br sistemas, dentre as quais se destacam as de auto-organização, auto-renovação e autotranscendência (Capra, 1989). No estudo da comunicação humana, Watzlawick, Beavin e Jackson (1993) sugerem que o comportamento dos indivíduos está relacionado com os comportamentos dos demais. Para esses autores, o importante não é apenas o conteúdo da comunicação, mas o aspecto relacional, uma vez que todo comportamento é uma forma de comunicação, e um indivíduo não pode deixar de se comunicar.

Na família, existem conteúdos que perpassam as gerações. O termo geração se refere ao fenômeno de pessoas com idades similares, que vivenciam um problema histórico concreto, de experiências comuns com o sistema político, social, econômico e cultural (Laufer \& Bengtson, 1974). Para Guardo (1982), geração é a expressão coletiva e o reflexo de estágios de mudança no desenvolvimento da personalidade, no comportamento e nos valores, em um grupo etário num período de tempo específico.

Pode-se destacar conteúdos de extrema importância na estrutura e funcionamento de uma família, que se evidenciam nos padrões transgeracionais. A partir da concepção de que é possível observar a família em seu aspecto intergeracional, 
faz-se necessário resgatar conceitos que caracterizam essa abordagem e que facilitam, portanto, o entendimento da estrutura e funcionamento familiar (Bowen, 1978).

Dentre tais conteúdos importantes identificados na família, destacam-se as lealdades invisíveis. Estas se referem à existência de expectativas diante das quais todas as pessoas assumem determinados compromissos, estabelecendo conexões firmes entre as gerações passadas e futuras (Borzormenyi-Nagy \& Spark, 1973).

Segundo Imber-Black (1991/1994), os segredos também podem estar presentes no contexto familiar, podendo mistificar e distorcer os processos de comunicação, moldar díades, formar triangulações, estabelecer alianças encobertas, divisões ou rompimentos e determinar a intimidade ou o distanciamento nas relações.

Em seu ciclo de vida, a família deve operar mudanças e transformações, como resposta às pressões externas e internas, para garantir sua unidade e manter sua continuidade. A família passa através do seu ciclo de vida por momentos chamados de transicionais que, de acordo com Mc Goldrick e Carter (1980), podem aglutinar expectativas, facilitar a passagem dos conteúdos intergeracionais, sejam eles determinados pelas lealdades familiares ou por conflitos e questões não resolvidas. No ciclo de vida podem ainda ocorrer cortes bruscos, que são muitas vezes dramáticos, e se referem a um distanciamento emocional ou rompimento de vínculos afetivos (Bowen, 1978).

Para Kramer (1985), o aumento da ansiedade na família pode caminhar em duas direções: na vertical, movendo-se para as próximas gerações; e na horizontal, ocorrendo nas transições evolutivas do ciclo de vida familiar. A habilidade para lidar com essas transições pode ser afetada pelo grau de ansiedade proveniente de ambos os lados, podendo gerar crises e paralisações, muitas vezes não identificadas pelos membros.

Outro conteúdo importante observado através das gerações familiares é o conflito. Em muitas situações os conflitos acabam se repetindo, uma vez que a linearidade familiar pode se manter através dos tempos, por conta do consenso existente entre as sucessivas gerações na mutualidade de experiências (Benincá \& Gomes, 1998).

A compreensão destas questões relativas à cultura familiar e destes conteúdos passados de geração a geração, contribui para o entendimento da própria cultura individual nas relações interpessoais (Imber-Black, 1997). A família é um organismo selecionador e qualificador das experiências do indivíduo, conferindo-lhe condições para a vivência individual e social, por intermédio de noções fundamentais como: procriação, cuidados com a saúde, criação e aperfeiçoamento de pautas sociais e culturais (Ruschel \& Castro, 1998).

Krom Pacolla $(1992,1994)$, por meio de suas pesquisas, do atendimento a famílias e dos pressupostos da teoria sistêmica e da abordagem intergeracional, desenvolve uma leitura instrumental mítica para facilitar a identificação e o trabalho preventivo e terapêutico com os mitos familiares. Segundo a autora, o mito constitui em sua essência a concepção de mundo própria da família, onde se cria a realidade familiar e o mapa do mundo individual. Os mitos podem dar origem aos significados atribuídos às experiências, determinando hierarquias de valores, influenciando a maneira como a família vê o mundo, e o sentido que as pessoas atribuem às suas vidas.

De acordo com esta leitura instrumental, é possível fazer a diferenciação entre o mito espinha dorsal, que determina o maior número de pautas e regras familiares, e o mito auxiliar, que como o próprio nome diz, determina pautas auxiliares. Além disso, é possível defini-los em construtivos e organizadores ou nocivos e desorganizadores.

Destaca-se, ainda, nessa abordagem (Krom, 2000), a figura mítica familiar que é a pessoa que transcende limitações, determina caminhos e dá origem a um percurso mítico na família, e o guardião do mito que é o indivíduo cuja incumbência é de propagar, bem como de executar os rituais presentes nos mitos. Outros elementos importantes dessa leitura que permitem ampliar a compreensão da mitologia familiar, são os momentos cruciais míticos, episódios do ciclo vital que ganham significado e importância, uma vez que podem desvendar e clarificar os mitos familiares, do mesmo modo como podem acionar a mudança destes sentidos na família.

Por tratar-se de um estudo que aborda não apenas o tema referente à família, como foi relatado anteriormente, serão destacados alguns princípios acerca da deficiência auditiva, com destaque às questões psicológicas relativas a perda da audição.

Qualquer distúrbio no processo de audição normal, seja qual for o tipo, a causa ou severidade, pode ser considerado como uma deficiência auditiva (Bevilacqua, 1998). As deficiências auditivas podem ser classificadas como unilaterais ou bilaterais, quando estão afetados um ou dois ouvidos. Quanto ao grau de comprometimento, seguem a classificação de leves, moderadas, severas e profundas; e podem ser condutivas, neurossensoriais, mistas e centrais, de acordo com a localização da alteração.

Algumas das principais conseqüências psicológicas da perda da audição, tanto na adquirida quanto na congênita, são a vivência do luto, a depressão e a ansiedade. Segundo estudos de Ballantyne, Martin e Martin (1993), recentes pesquisas têm descartado a existência de diferenças biológicas entre surdos e ouvintes, e ressaltado que é preciso considerar as diferenças psicológicas entre eles.

Em outros estudos, Rutman e Boisseau (1995) observam que a conseqüência mais devastadora da deficiência auditiva é o impacto causado na identidade, esta definida como a maneira pela qual o indivíduo entende, descreve e protege o seu senso de self, incluindo o senso das suas habilidades pessoais, capacidades, necessidades, valores, aspirações e sonhos.

Quanto à surdez adquirida, Kerr e Cowie (1997) indicam que as variáveis psicológicas, mais do que as audiológicas, podem diferenciar as experiências subjetivas. O impacto causado pela perda de audição é determinado por fatores experienciais com igual ou maior intensidade do que o causado por fatores biomédicos tradicionais. Desse modo, tal impacto não pode ser entendido simplesmente pela medida da intensidade da surdez, mas deve ser compreendido como uma experiência multidimensional.

As relações interpessoais são consideradas cruciais para a manutenção da auto- imagem e dos papéis sociais. Os autores Hallberg e Carlsson (1991) apontam que a deficiência auditiva afeta negativamente as interações sociais, inclusive as familiares, provocando na pessoa com deficiência, 
frustrações, irritação e sentimentos de inferioridade. Nesse mesmo sentido, Hétu, Jones e Getty (1993) afirmam que o choque causado pela perda de audição adquirida não tem implicações somente para a pessoa, mas também para o cônjuge ou parceiro.

A relação entre família e deficiência auditiva foi pesquisada por Nybo, Scherman e Freeman (1998). De acordo com os autores, o nascimento de filhos surdos faz com que, comumente, os pais solicitem ajuda dos avós da criança no processo de reabilitação. Em geral, os avós providenciam apoio diante do diagnóstico da surdez, constituindo papel importante no processo de ajustamento da família. Além disso, os recursos financeiros dos avós foram caracterizados como fator secundário, diante do valor atribuído ao seu papel afetivo na resolução de conflitos.

Para Harvey (1985), a terapia familiar deve se preocupar com as dificuldades existentes na comunicação entre ouvintes e surdos e considerar até que ponto as falhas comunicativas não estão sendo úteis para o sistema familiar. Portanto, o profissional que trabalha com uma família na qual um dos membros é surdo, deve, sobretudo, respeitar as características do modo de comunicação adotado pelos membros do sistema, que pode ser específico de cada família (Sloman \& Springer, 1987).

As ações direcionadas para lidar com a estigmatização e o comportamento da população, diante das pessoas com deficiência auditiva, podem evitar que eles se sintam inferiorizados, ansiosos e deprimidos (Hallberg \& Carlsson, 1991). Outros autores como Rutman e Boisseau (1995) consideram que os deficientes auditivos e suas famílias, ao enfrentarem as perdas, as tensões na comunicação e as dificuldades interpessoais, devem ser impreterivelmente assistidos por um trabalho de reabilitação.

Partindo do princípio de que é possível entender a família a partir da análise dos conteúdos que passam através das gerações, e do pressuposto de que o diagnóstico da deficiência auditiva provoca modificações significativas no sujeito e na sua família, pode-se confirmar a importância de desenvolver um estudo que faça a relação entre estas duas questões, família e deficiência auditiva. A repetição dessa deficiência em diferentes gerações familiares pode ocasionar transformações nos conteúdos intergeracionais e no significado que o sujeito atribui à própria deficiência?

Portanto, é com base na leitura instrumental mítica (Krom, 1997, 2000; Krom Paccola, 1992, 1994), anteriormente citada, que será possível então: identificar e reconhecer os mitos na família de um sujeito adulto com deficiência auditiva, por meio da reconstrução de suas histórias familiares; estabelecer as relações entre os mitos presentes e o significado que o sujeito atribui atualmente à sua deficiência auditiva.

\section{Método}

\section{Sujeito}

Participou deste estudo de caso clínico um adulto do sexo masculino com 37 anos de idade. Matriculado no Hospital de Reabilitação de Anomalias Craniofaciais da Universidade de São Paulo (HRAC - USP), Bauru-SP, faz parte do Programa de Implante Coclear do Centro de Pesquisas Audiológicas
(CPA) da Instituição. A queixa da perda auditiva teve início na adolescência e vem progredindo até o diagnóstico atual, que é o de deficiência auditiva neurossensorial profunda bilateral.

\section{Instrumentos e procedimento}

Os dados foram obtidos no CPA, por meio da Entrevista Intergeracional semi-estruturada, de acordo com o roteiro elaborado por Krom Paccola (1994). Esse instrumento tem como objetivo possibilitar a reconstrução da história familiar por meio do relato das principais características de familiares atuais e pregressos. Cabe ressaltar que por tratar-se de um estudo de caso, apenas um membro da família foi entrevistado, fornecendo, portanto, uma visão parcial da história familiar. As perguntas foram subdivididas em três principais grupos de investigação: caracterização dos membros, relacionamento familiar e deficiência auditiva. Foram realizados quatro atendimentos, cada um deles com duração média de duas horas. No primeiro encontro, realizou-se o contrato de trabalho e o sujeito se comprometeu com a participação na pesquisa. Nos três seguintes, coletaram-se, respectivamente, informações acerca da família nuclear (terceira geração) e das famílias que compõem a primeira e a segunda geração. Utilizou-se o recurso da gravação para que os relatos fossem fidedignamente reproduzidos.

\section{Análise de dados}

Inicialmente, as informações gravadas foram transcritas de modo literal. Elaborou-se o Genograma (Bowen, 1978), com a finalidade de visualizar estrutura, organização e funcionamento das três gerações. A etapa seguinte foi a de reconstrução das histórias familiares, nas quais foram preservados os eventos críticos presentes nos ciclos de vida das famílias. Por se tratar de um estudo qualitativo, a análise de dados foi realizada, a partir de então, com base nos pressupostos teóricos adotados.

\section{Relato Cursivo das Histórias Familiares}

A partir da apresentação do Genograma (figura 1), no qual se destacam as pessoas com deficiência auditiva e o sujeito (Josué) de pesquisa, foi descrito o relato cursivo das histórias. Os nomes utilizados foram fictícios, a fim de resguardar a identidade dos familiares do sujeito.

\section{Família Nuclear}

\section{Relato cursivo da história familiar do Sr. Genaro (pai de Josué)}

Genaro e Carmem se casaram e foram morar em uma colônia agrícola. Quando Josué nasceu, os pais já tinham duas filhas e, mais tarde, tiveram Nilton. Nos primeiros anos de vida, as duas filhas mais velhas já apresentavam dificuldades de audição. Nilton faleceu com um ano, pois era muito doente; Josué foi quem auxiliou os pais nos cuidados com o irmão caçula.

Naquele mesmo ano, a família foi para a capital em busca de melhores condições financeiras. Nasceu André e todos 


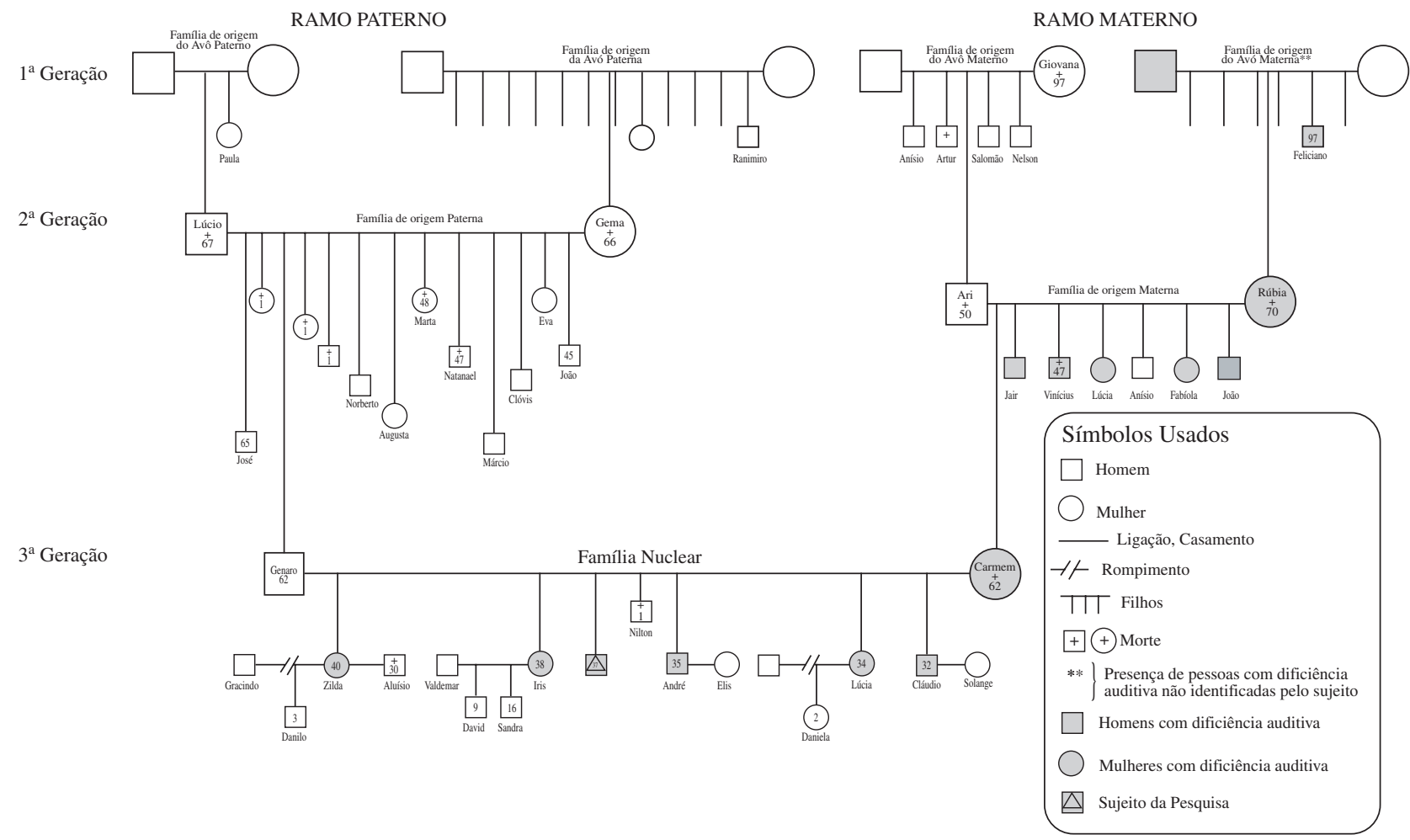

Figura 1. Genograma.

voltaram para o interior, devido aos problemas de saúde desta criança, que também recebeu diagnóstico de deficiência auditiva. Ao retornarem, foram morar em uma fazenda, local onde nasceram os últimos filhos, Lúcia e Cláudio, ambos com problema de audição. Anos depois, toda a família foi morar na cidade. Carmem, então, começou a trabalhar e deixava os filhos em uma creche.

Josué completou o primeiro ano do ensino médio. Os outros cursaram a quarta série do fundamental, exceto Lúcia, que não desenvolveu a fala devido à severidade da deficiência auditiva. Ela ficava em casa e cuidava dos afazeres domésticos.

Na fase da adolescência, Josué e André começaram a perder a audição. Josué se envolveu com drogas e só conseguiu abandonar o uso do álcool e da maconha dez anos mais tarde. Sempre evitou situações sociais e contatos interpessoais duradouros, tanto com amigos quanto com namoradas. Acreditava que as drogas poderiam lhe ajudar, tornando-o mais forte, mas ao perceber os reais efeitos causados por elas, esforçou-se para abandonar o vício e conseguiu.

Genaro começou a beber diariamente, a bater em todos, inclusive na esposa, e a se envolver com mulheres e jogos. Dois anos depois, foi demitido. Comprou um bar na cidade e a situação se agravou, pois não se preocupava com o novo trabalho. Não incentivava o desenvolvimento dos filhos, dizia que eles não conseguiriam fazer nada porque eram surdos. Envolvia-se em todos os assuntos e nas tomadas de decisões, como se eles não fossem capazes de solucionar problemas. Carmem quis se separar do marido, mas continuou mantendo a relação para poupar os filhos. Genaro perdeu o bar e todo o dinheiro. Parou de beber, não saía de casa e as brigas diminuíram.

Dos filhos, Zilda foi a primeira a se casar e logo ficou viúva. Mais tarde, engravidou de um homem casado e foi expulsa de casa pelos pais, que se arrependeram e a chamaram de volta antes mesmo do nascimento da criança. Iris, André e Cláudio também se casaram. Todos continuaram morando na mesma cidade.

Lúcia foi estuprada dentro da casa dos pais. Ela, Genaro, Carmem e Josué mantiveram e ainda mantêm segredo a respeito deste fato. Não foi possível realizar um aborto, por conta do período de gestação, e Lúcia teve o bebê. Carmem acreditava que a criança seria uma companhia para a filha surda-muda e que, dessa forma, ela não ficaria sem cuidados.

Josué não se casou e teme ter filhos com deficiência auditiva. Para ele, sempre foi difícil aceitar suas limitações. Queixa-se do preconceito social, das dificuldades de trabalho e da comunicação interpessoal. Foi o único a procurar um tratamento sistemático em uma cidade vizinha e insiste para que os irmãos e a mãe façam o mesmo.

Atualmente, Genaro e Carmem residem na mesma casa com os filhos, Zilda, Josué, Lúcia, e os netos, Daniela e Danilo. Carmem ainda trabalha e Genaro é aposentado. Lúcia cuida da casa e Josué é pedreiro. A maior preocupação de Carmem e Josué é manter a união da família. Aos domingos, costumam almoçar juntos. Diante de conflitos pedem ajuda especialmente a Josué e Genaro é excluído das discussões. Não têm muito contato com outras pessoas, costumam desconfiar de desconhecidos e recebem poucos amigos em casa. 


\section{Ramo Paterno}

\section{Relato cursivo da história familiar do Sr. Lúcio (avô paterno de Josué)}

Lúcio e Gema se conheceram em uma colônia agrícola, onde seus pais trabalhavam e moravam. Tinham cerca de 15 anos quando se casaram. A partir do casamento, Lúcio continuou exercendo a atividade rural no interior do estado, enquanto Gema cuidava dos afazeres domésticos. As dificuldades financeiras aumentavam e eles se queixavam do trabalho diário.

O primeiro filho, José, nasceu anos depois. O casal teve ainda outros doze filhos dos quais sobreviveram dez, pois perderam duas meninas e um menino com apenas um ano de vida. Os filhos tinham que ajudar os pais e não puderam freqüentar a escola por muito tempo. Desde a infância até a idade adulta, costumavam brigar, batiam uns no outros, ofendiam-se verbalmente e gostavam de beber em bares diariamente.

Com o passar do tempo todos se casaram e tiveram filhos, exceto João, o caçula da família. Em busca de melhores oportunidades, começaram a procurar novas ocupações. Norberto e Márcio se tornaram motoristas. Genaro ainda permaneceu por algum tempo na lavoura e as mulheres acompanharam seus maridos cuidando de suas casas e de suas famílias.

Norberto e Clóvis tiveram filhos com um tipo de deficiência física, que lhes dificultava a locomoção, motivo pelo qual cada um se mobilizou para superar as dificuldades, sem, contudo, contar com a ajuda dos demais parentes.

$\mathrm{Na}$ adolescência, João se envolveu com drogas. Não ia à escola e não permaneceu em nenhum emprego até a idade adulta. Era sustentado pelos pais, mas não aceitava normas e regras que lhe eram impostas.

Com a morte de Lúcio, e um ano mais tarde, com a de Gema, os familiares começaram a se distanciar. Lúcio era quem se responsabilizava pelas reuniões que se tornaram cada vez mais esporádicas, apesar das tentativas que Marta realizava para uni-los após a morte do pai.

Natanael faleceu em um acidente de carro e Marta morreu com câncer, oito anos após o marido ter cometido suicídio na frente de uma de suas filhas. Como ela era quem procurava reunir as pessoas, após seu falecimento, os encontros passaram a ocorrer somente quando algum familiar morria.

\section{Relato cursivo da história da família de origem do avô paterno (bisavô paterno de Josué)}

A família imigrou para o Brasil no início do século passado em busca de melhores condições de vida. Era preciso muito trabalho para garantir a sobrevivência de todos. Após dez anos da chegada, os filhos Lúcio e Paula se casaram com Gema e Ranimiro.

\section{Relato cursivo da história da família de origem da avó paterna (bisavó paterna de Josué)}

Seus bisavós paternos vieram para o Brasil e passaram a morar em colônias agrícolas com os treze filhos e continuaram a trabalhar na lavoura. As dificuldades financeiras eram grandes e a família fazia esforços para manter a subsistência dos membros. Na tentativa de abandonar a casa dos pais, Gema e Ranimiro se casaram com dois irmãos, Lúcio e Paula, filhos de lavradores.

\section{Ramo Materno}

Relato cursivo da história familiar do Sr. Ari (avô materno de Josué)

Ari e Rúbia se casaram e tiveram sete filhos, Carmem, Jair, Vinícius, Lúcia, Anísio, Fabíola e João. Todos tinham deficiência auditiva como a mãe, exceto Anísio. Era uma perda de audição que, ao longo do tempo, tendia a se agravar. À medida que iam sendo confirmados os diagnósticos, cresciam as dificuldades para aceitar esta deficiência, o que acarretou muitas vezes uma busca assistemática pela reabilitação, não adesão aos tratamentos e a espera pelo milagre de voltar a ouvir.

Não passavam dificuldades financeiras. Rúbia preparava festas, solicitava a presença dos filhos e, mais tarde, dos netos. Eram muito amigos e a maior preocupação era o sentido da união familiar.

Todos tinham que ajudar os pais com a agricultura, trabalhando muito. Havia incentivo para que estudassem, mas a maioria não chegou a completar o ensino fundamental. Foram casando-se, exercendo outras ocupações e constituíram família na capital. Carmem foi a única que permaneceu no interior. João e Vinícius não se casaram e, como Anísio, começaram a beber. $\mathrm{O}$ primeiro tornou-se dependente, motivo que gerou preocupações à família, especialmente em Rúbia.

Mais tarde, Ari e Rúbia se mudaram para a capital e levaram com eles os filhos solteiros. Ari adoeceu, sentia muitas dores musculares, condição que o deixou de cama e o levou à morte. Rúbia, sofrendo com a ausência do marido e triste com o estado de João, morreu aos 70 anos. Como os membros da família sempre se encontravam e mobilizavam recursos para auxílio mútuo, decidiram que João iria morar com os irmãos e ficaria por algum tempo na casa de cada um deles.

O falecimento de Vinícius sensibilizou bastante a família, pois ele era o principal mantenedor da união familiar. Lúcia passou a organizar encontros, visitas e comemorações a partir de então.

Relato cursivo da história da família de origem do avô materno (bisavô materno de Josué)

A família também veio para o Brasil no início do século passado para trabalhar na lavoura. Os filhos, que vieram ainda pequenos, foram crescendo e ajudavam os pais na propriedade da família. Reuniam-se freqüientemente, organizavam festas, comemorações e gostavam de beber. Giovana geralmente cuidava da organização dessas reuniões, estava sempre disposta a ajudar as pessoas. Com a morte do marido e o aparecimento da deficiência auditiva em alguns membros da família e, principalmente, com o alcoolismo de Artur e Nelson, Giovana passou a se preocupar muito. Faleceu ainda lúcida, com mais de 90 anos. Após um ano, faleceu também Artur. Anísio, por conta de um derrame cerebral, perdeu a visão.

\section{Relato cursivo da história da família de origem da avó} materna (bisavó materna de Josué)

$\mathrm{O}$ casal veio para o Brasil com alguns filhos ainda pequenos e outros na adolescência. No país de origem, trabalhavam com lavoura e aqui mantiveram o mesmo ofício. A família conseguiu comprar terras e os sete filhos auxiliavam os pais nessa atividade. Conversavam muito entre si e prestavam 
ajuda uns aos outros, mas não tinham amizades e contatos com pessoas que não fossem da família.

Como o pai, alguns filhos começaram a perder a audição. Aos 80 anos, Feliciano começou a perder a audição e passou a morar sozinho depois de viúvo. Alegando que não gostaria de dar trabalho a ninguém, ainda hoje, recusa convites para morar na casa de irmãos.

\section{Análise das Histórias Familiares}

É possível identificar nestas famílias, a presença de três mitos percorrendo as gerações: (1) o da deficiência auditiva, que implica no entendimento da família como a "família de surdos"; (2) o da união, que favorece o pertencimento e a manutenção dos padrões afetivos; e (3) o da luta pela sobrevivência, que significa a possibilidade de transcender as situações de muito sofrimento. $\mathrm{O}$ mito da união pode ser considerado como a espinha dorsal e os outros dois como auxiliares, uma vez que determinam pautas complementares e se encaixam no mito principal.

Ao analisar os sentidos que foram se formando e se mantendo na família, verifica-se no ramo paterno da família de Josué, o mito da luta pela sobrevivência. A dedicação do grupo familiar à atividade agrícola, tanto na primeira, quanto na segunda geração, antes de ser considerada mito, deve ser entendida como decorrente da situação sócio-histórica nacional. De acordo com a política migratória, europeus que vinham para o Brasil trabalhavam com a agricultura, pois esta era a atividade viável econômica e politicamente. Dessa forma, as relações familiares assumiam os padrões culturais da época.

Na primeira geração, a atividade agrícola foi a forma de garantir o sustento e a subsistência familiar. Estão claras as mobilizações de todos os membros da família na luta pela sobrevivência. Na família de origem paterna (segunda geração), destacam-se pautas que configuram a luta pela sobrevivência desde a primeira geração. $\mathrm{O}$ nascimento dos filhos representa a possibilidade de ampliar a mão-de-obra para cuidar da terra. Ao atingirem a idade adulta, os filhos partem em busca de novas ocupações e melhores oportunidades de trabalho. Os esforços passam a ser cada vez mais individuais e as pessoas se afastam umas das outras. Nos relatos do sujeito, notam-se expectativas pela busca de aproximação e afeto, atitudes presentes nas tentativas de Marta (tia de Josué) para unir a família.

Estão presentes conflitos entre irmãos e entre os próprios pais, agravados por episódios de violência, casos de alcoolismo e envolvimento com o uso de drogas. Eventos traumatizantes mostram-se presentes, indicados pelo suicídio do marido de Marta e pelo falecimento de seu irmão Natanael. O enfrentamento das dificuldades sem o apoio mútuo dos parentes, a repetição de um tipo de deficiência física em dois primos de Josué, é estressante para a família, que amplia a necessidade e as expectativas de união e afeto. No ramo materno da família, são muitas as maneiras pelas quais se manifestam os conteúdos presentes no mito da união e no da deficiência auditiva.

Na primeira geração, além das características determinadas pelos mitos anteriores, destacam-se pautas de luta conjunta pela sobrevivência, embora não sejam marcantes a ponto de se constituírem enquanto Mito. Como imigrantes, as famílias de origem do avô e da avó materna de Josué vêm para o Brasil para trabalhar na lavoura. Os filhos, à medida que crescem, passam a auxiliar os pais no trabalho, situação comum na época entre imigrantes, uma vez que se unem para garantirem a subsistência do grupo. A organização de encontros e reuniões é freqüente, da mesma forma que a existência de diálogos e de cooperação mútua, determinando a presença das pautas afetivas que caracterizam o mito da união, principal sentido nesta família.

$\mathrm{Na}$ primeira e na segunda geração, a presença de rituais como organizações de festas e comemorações, momentos nos quais todos os membros da família participam e compartilham suas dificuldades e seus sucessos, contribuem para a manutenção do mito da união. São enfatizados os papéis de Giovana (bisavó de Josué) e de Rúbia (avó materna de Josué), que podem ser consideradas como guardiãs deste mito, visto que cabe a elas a responsabilidade pela propagação e execução dos rituais. Após a morte de Rúbia, Vinícius, um de seus filhos, passa a ser o guardião. Anos mais tarde, com seu falecimento, Lúcia, outra filha de Rúbia, é quem se incumbe de preservar as pautas míticas.

O sentido mítico da união se clarifica principalmente nas crises de difícil resolução, destaca-se o registro de casos de alcoolismo e de deficiência auditiva no ciclo de vida da família. A repetição do alcoolismo mobilizou, no contexto familiar, situações de ajuda e cuidado. Exemplo disso é o caso de João (tio de Josué), dependente do álcool, que viveu com os pais até a morte deles. A partir de então, os membros da família decidiram que ele deveria ficar algum tempo na casa de cada um dos irmãos, a fim de que as despesas e a atenção fossem divididas entre todos. Nos momentos em que são confirmados os diagnósticos de deficiência auditiva na família, verificam-se o apoio e auxílio de todos, fortalecendo o sentido presente da união, e respondendo à estrutura de lealdade por ele determinada.

A ocorrência da deficiência auditiva na primeira geração pode ser considerada como evento crítico da trajetória familiar, causadora de ansiedade e de estresse, um momento crucial mítico, por desvendar e clarificar a presença das pautas míticas. O reaparecimento das complicações auditivas na segunda e, mais tarde, na terceira geração, fortalece os vínculos afetivos. Ao mesmo tempo, surge o sentido da "família surda" pontuada pelas várias repetições da deficiência auditiva e pelas limitações desta situação familiar.

A família se une em torno de si mesma fortalecendo as pautas de união, e as relações sociais se restringem progressivamente ao círculo familiar. A expectativa maior surge com a falta de conhecimento acerca da própria deficiência, e se restringe à espera por um milagre de voltar a ouvir. Dessa forma, o mito da deficiência auditiva e o da união se encaixam e se fortalecem mutuamente.

$\mathrm{Na}$ família nuclear de Josué, estão presentes os mitos das famílias de origem, vistos anteriormente. Destaca-se a manutenção dos rituais, que como atitudes obrigatórias contribuem para a preservação mítica. Assim como nas gerações anteriores, cabe aos guardiões do mito, representados por Carmem (mãe de Josué), e atualmente por Josué, a responsabilidade pela organização de encontros familiares e pela aproximação de todos os membros. $\mathrm{O}$ acolhimento à Zilda 
(irmã de Josué) que ficou grávida de um homem casado, foi um evento significativo, mostrando a união familiar em momento crítico.

Outra questão relacionada ao tema é a decisão de Carmem (mãe de Josué) quanto a permanecer casada com o marido. O motivo que a faz continuar na relação, apesar da agressividade dele, bem como o envolvimento com outras mulheres, jogos e bebidas, é a manutenção da família e a proteção dos filhos.

O segredo existente em relação ao estupro de Lúcia, irmã mais nova de Josué, implica na consolidação de uma aliança estabelecida para manter oculto o ocorrido. A situação ilustra, novamente, a existência das pautas de ajuda e cuidado, pelo fato de os familiares acreditarem que o nascimento de uma criança, mesmo tendo sido gerada por ocasião de uma violência sexual, faria com que Lúcia tivesse companhia quando não pudesse mais ser cuidada pelos pais.

Quanto ao mito da deficiência auditiva, pode-se dizer que a conseqüência dessa deficiência geneticamente herdada, antes de ser uma realidade familiar subjetiva, refere-se a uma situação objetiva que acarreta tanto as dificuldades auditivas quanto psicológicas, dentre as quais destacam-se o sentimento de inferioridade, baixa auto-estima e esquivas sociais.

São nítidos os padrões de repetição intergeracional na família nuclear, marcada por estresse constante, relativo ao surgimento dessa deficiência em todos os membros, exceto em Genaro. Há a crença difundida, de que pessoas com deficiência não são capazes e não podem aprender. Com base nisso, evidencia-se a falta de incentivo aos estudos e a intervenção dos pais nas decisões e na vida profissional dos filhos. Criase, portanto, o sentido da "família de surdos". Os assuntos relativos à deficiência auditiva não são discutidos entre os familiares e eles não procuram tratamentos sistemáticos. Os membros se mantêm unidos para evitar preconceitos e estigmatizações, garantindo um forte movimento das forças homeostáticas, que impedem ou dificultam o intercâmbio com o meio externo e, conseqüentemente, a resolução de problemas relacionados à deficiência.

Josué por ter conseguido abandonar o uso do álcool e das drogas, buscar um processo de reabilitação em um centro especializado de uma cidade vizinha, e por ter o conhecimento de que uma pessoa com deficiência pode desenvolver ao máximo suas potencialidades, pode ser considerado uma figura mítica familiar. Atualmente, tem dificuldade para acreditar nas próprias capacidades, enfrentar situações de relacionamento interpessoal e tem medo de gerar filhos com deficiência auditiva. Mas, ao mesmo tempo, Josué assegura um outro caminho familiar para lidar com o problema causado pela deficiência auditiva, com a possibilidade de refletir, questionar a respeito da própria deficiência e abrir as fronteiras rígidas de sua família, criando a possibilidade de flexibilizá-las.

\section{Discussão}

A teoria sistêmica (Bertalanffy, 1967; Capra, 1989), a terapia familiar estrutural (Umbarger, 1983), a abordagem intergeracional de família (Bowen, 1978) e a leitura instrumental mítica (Krom, 1997, 2000; Krom Pacolla, 1992, 1994) constituem os pressupostos de análise e discussão dos dados.
Partindo dessa literatura, é possível entender a família e o desenvolvimento do comportamento dos indivíduos que dela fazem parte.

Com base na leitura instrumental mítica, foi possível identificar os mitos da união, da deficiência auditiva e o da luta pela sobrevivência que percorrem intergeracionalmente a família do sujeito da pesquisa. Observou-se então, a partir do reconhecimento dos conteúdos míticos, o significado que a família atribui às experiências, às hierarquias de valores e o sentido que as pessoas atribuem às suas vidas. Como aponta Imber-Black (1997), a compreensão de fatores da cultura familiar facilitou o entendimento da cultura individual nas relações interpessoais.

No ramo paterno da família de Josué, os esforços para vencer as adversidades e lutar por melhores condições, acabaram caracterizando o mito da luta pela sobrevivência, uma vez que percorreu a primeira e a segunda geração. Embora, caracterizado como mito, deve-se ressaltar que as relações familiares assumiam os padrões culturais da época. $\mathrm{O}$ trabalho vinha em primeiro lugar, como forma de garantir o sustento, principalmente entre os imigrantes que se estabeleceram em colônias do Brasil. A repetição de conflitos (violência entre os membros) que manteve a linearidade familiar através dos tempos (Benincá \& Gomes, 1998), bem como a ocorrência de eventos traumatizantes (uso de drogas, suicídio, casos de deficiência física), aumentaram a ansiedade tanto no sentido vertical, movendo-se para próximas gerações, como no horizontal, ocorrendo nas transições evolutivas do ciclo de vida familiar (Kramer, 1985).

No ramo materno, os mitos da união e o da deficiência auditiva foram identificados, o primeiro caracterizado como espinha dorsal e o segundo como auxiliar, de acordo com princípios da leitura instrumental mítica.

Essa leitura permitiu o reconhecimento da presença de rituais como festas e comemorações propagadas pelos guardiões do mito, que contribuíram para a manutenção do sentido da união familiar. Ainda de acordo com Krom (1997, 2000); Krom Pacolla (1992, 1994) pode-se dizer que situações de difícil resolução como a repetição de casos de alcoolismo e de deficiência auditiva no ciclo de vida familiar (McGoldrick \& Carter, 1980), clarificaram e desvendaram o significado mítico, uma vez que mobilizaram situações de ajuda e cuidado.

A repetição da deficiência auditiva ao longo das gerações fez com que os familiares se unissem contribuindo com a rigidez das pautas de ajuda e cuidado, com a restrição das relações sociais ao círculo familiar e com a existência de expectativas com as quais todos firmaram compromisso (BorzormenyiNagy \& Spark, 1973). Os impactos causados pelas perdas de audição repetidas nas gerações (Ballantyne, Martin \& Martin, 1993; Hallberg \& Carlsson, 1991; Hétu, Jones \& Getty, 1993; Kerr \& Cowie, 1997; Nybo, Scherman \& Freeman, 1998; Rutman \& Boisseau, 1995) reforçaram as pautas do mito espinha dorsal (união) de modo que este e o auxiliar (deficiência auditiva) se encaixaram e se fortaleceram mutuamente.

Na família nuclear, com base nos conceitos propostos pela leitura instrumental mítica, observou-se a manutenção dos mitos identificados nas famílias de origem. A expulsão de Zilda (irmã de Josué) da casa dos pais (Bowen, 1978), seguida do seu acolhimento, o esforço para manter a integridade da 
família realizado por Carmem (mãe de Josué), a manutenção do segredo (Imber-Black, 1991/1994) em relação ao estupro de Lúcia (irmã de Josué) são eventos que permitiram visualizar as pautas do mito da união.

A repetição intergeracional da deficiência auditiva aumentou a ansiedade no contexto da família. Fica reforçada a necessidade de que famílias com um ou mais indivíduos com deficiência auditiva sejam assistidas por profissionais habilitados (Hallberg \& Carlsson, 1991; Rutman \& Boisseau, 1995).

É nesse contexto que Josué se desenvolve e aos poucos, vai construindo o significado que tem a respeito da sua deficiência auditiva. Atualmente, tem algumas dificuldades (sentimento de inferioridade, inabilidades sociais, medo de gerar filhos com deficiência auditiva), em consequiência da perda de audição, embora possa ser considerado como uma figura mítica (Krom, 1997, 2000; Krom Pacolla, 1992, 1994) por transcender limitações até então vivenciadas por familiares. Conseguiu abandonar o uso de drogas e buscou a reabilitação sistematizada, dando origem a um novo caminho familiar para enfrentar as dificuldades. A sua aquiescência e participação, neste trabalho, sinalizam a possibilidade da abertura para aceitar ajuda externa e lidar de outra maneira com a deficiência.

\section{Conclusão}

A partir dessas considerações, levando em conta a análise feita com base na leitura instrumental mítica, amplia-se a compreensão do significado que a deficiência auditiva tem para o sujeito desta pesquisa.

Com a clarificação dos mitos familiares e com a identificação dos conteúdos intergeracionais é possível compreender a visão do contexto da deficiência na família, garantir a possibilidade de encontrar novos caminhos para lidar com a deficiência auditiva, e entender o significado que o sujeito atribui atualmente à própria deficiência.

\section{Referências}

Ballantyne, J., Martin, M.C. \& Martin, A. (1993). Surdez. Porto Alegre: Artes Médicas.

Benincá, C.R.S. \& Gomes, W.B. (1998). Relatos de mães sobre transformações familiares em três gerações. Estudos de Psicologia, 3(2), 177-205.

Bertalanffy, L.V. (1967). Teoria geral dos sistemas. Petrópolis: Vozes.

Bevilacqua, M.C. (1998). Conceitos básicos sobre a audição e deficiência auditiva. Bauru: Hospital de Pesquisa e Reabilitação de Lesões Lábio-Palatais, Universidade de São Paulo.

Bowen, M. (1978). Family therapy in clinical pratice. Nova York: Jason Aronson.

Borzormenyi-Nagy I. \& Spark, G.M. (1973). Intergenerational family therapy. Nova York: Harper \& Row Publishers.

Capra, F. (1989). O ponto de mutação. São Paulo: Cultrix.

Guardo, C.J. (1982). Student generations and value change. The Personnel and Guidance Journal, 60, 500-503.

Hallberg, L. \& Carlsson, S. (1991). A qualitative study of strategies for managing a hearing impairment. British Journal of Audiology, 25, 201-211.
Harvey, M.A. (1985). Toward a dialogue between the paradigm of family therapy and deafness. American Annals of the Deaf, 130(4), 305-314.

Hétu, R., Jones, L. \& Getty, L. (1993). The impact of acquired hearing impairment on intimate relationships: implications for rehabilitation. Audiology, 32, 363-381.

Imber-Black, E. (1994). Os segredos na família e na terapia familiar. (D. Batista, Trad.) Porto Alegre: Artes Médicas. (Trabalho original publicado em 1991).

Imber-Black, E. (1997). Developing cultural competence: contributions from recent family therapy literature. American Journal of Psycotherapy, 51(4), 607-615.

Kerr, P.C. \& Cowie, R.I.D. (1997). Acquired deafness: a multidimensional experience. British Journal of Audiology, 31, 177-188.

Kramer, R.J. (1985). Family Interfaces. Transgerational Patterns. Nova York: Brunner/Mazel.

Krom, M. (1997). O encaixe dos mitos na construção do casamento - uma leitura instrumental mítica. Tese de Doutorado, Pontifícia Universidade Católica de São Paulo, São Paulo.

Krom, M. (2000). Família e mitos. São Paulo: Summus.

Krom Paccola, M. (1992). O mito nas histórias familiares de adolescentes com problemas. Dissertação de Mestrado, Pontifícia Universidade Católica de São Paulo, São Paulo.

Krom Paccola, M. (1994). Leitura e diferenciação do mito. São Paulo: Summus.

Laufer, R.S. \& Bengtson, V.L. (1974). Generations, aging, and social stratification: on the development of generational units. Journal of Social Issues, 30, 181-205.

Mc Goldrick, M. \& Carter, E. (1980). The family life circle. A framework for family therapy. Nova York: Gardner Press.

Nybo, W.L., Scherman, A. \& Freeman, P.L. (1998). Grandparents' role in family systems with a deaf child. An exploratory study. Amerincan Annals of the Deaf, 143(3), 260-267.

Ruschel, N.E. \& Castro, O.P. de. (1998). O vínculo intergeracional: o velho, o jovem e o poder. Psicologia, Reflexão e Crítica, 11 (3), 523-539.

Rutman, D. \& Boisseau, B. (1995). Acquired hearing loss: social and psychological issues and adjustment processes. International Journal of Rehabilitation Research, 18, 313-323.

Sloman, L. \& Springer, S. (1987). Strategic family therapy interventions with deaf member families. Canadian Journal of Psychiatry, 32(7), 558-562.

Umbarger, C.C. (1983). Terapia familiar estructural. Buenos Aires: Amarrorter Editores.

Watzlawick, P., Beavin, J.H. \& Jackson, D. (1993). Pragmática da comunicação humana. São Paulo: Cultrix.

Recebido em 17.09.2001

Primeira decisão editorial em 14.04.2002

Versão final em 28.06.2003

Aceito em 28.08.2003 